\title{
As interações em sala de aula nos terceiros anos do ensino fundamental
}

\author{
Vera Lucia Trevisan de Souza \\ Ana Flávia Silva Luz
}

\section{RESUMO}

A pesquisa ora relatada teve por objetivo investigar as relações entre os alunos e entre os alunos e professoras de classes do $3^{\circ}$ ano do ensino fundamental, buscando identificar que tipos de interação favorecem ou não a convivência na escola. A demanda por compreender as interações em sala de aula surge da queixa das professoras de que, já no $3^{\circ}$ ano, os alunos pareciam se desinteressar pelos conhecimentos formais, preferindo envolver-se em conversas ou brincadeiras, ainda que investissem em estratégias para chamar-lhes a atenção. Assumindo os pressupostos da Psicologia Histórico-Cultural, que concebe o meio como fonte de desenvolvimento e as interações como produzidas no e pelo social, desenvolvemos uma pesquisaintervenção como forma de aproximação do fenômeno investigado. Ao todo, foram realizados 18 encontros com cada turma, todos registrados em diários de campo e alguns gravados em áudio. Constatamos, como resultado que as interações mediadas pelas tentativas de controle do comportamento das crianças pelas professoras não favoreciam sua participação nas atividades propostas, mas, ao contrário, produziam atitudes que visavam transgredir a regra. De outro lado, quando os alunos percebiam a implicação da pesquisadora e professoras em envolvê-los, atendendo-os, por exemplo, em seus interesses de gênero de histórias e prática de contação, aumentava a participação e o envolvimento com as atividades.

Palavras-chaves: interações em sala de aula; ensino fundamental; psicologia histórico-cultural; psicologia escolar.

\section{ABSTRACT \\ Interactions in the classroom in third year of elementary school}

The research's object was to investigate the relations between students and between students and class teachers of the third ear of elementary school, trying to identify what types of interaction favor or not the coexistence in the school. The demand for understanding the interactions in the classroom arises from the complaint of the teachers that in the third year students already seemed to be disinterested in formal knowledge, preferring to engage in conversations or jokes, even though they invested in strategies to draw attention to them. Based on the assumptions of Historical-Cultural Psychology, which conceives the medium as a source of development and interactions as produced in and by the social, we developed an intervention research as a way of approaching the investigated phenomenon. In total, 18 meetings were held with each class, all recorded in field journals and some recorded in audio. As a result, it was observed that the interactions mediated by the teachers' attempts to control children's behavior did not favor their participation in the proposed activities, but instead produced attitudes that aimed to transgress rules. On the other hand, when students perceived the involvement of the researcher and teachers in involving them, for example in their genre interests in stories and practice ofstorytelling, participation and involvement with activities increased.

Keywords: interactions in the classroom; elementary school; historical-cultural psychology; school psychology.

\section{Sobre os Autores}

V.L.T.S.

orcid.org/0000-0003-2062-0680 Pontifícia Universidade Católica (PUC) - Campinas, SP vera.trevisan@uol.com.br

A.F.S.L.

orcid.org/0000-0003-0395-0223 Pontifícia Universidade Católica (PUC) - Campinas, SP anaf_luz@hotmail.com

\section{Direitos Autorais}

Este é um artigo de acesso aberto e pode ser reproduzido livremente, distribuído, transmitido ou modificado, por qualquer pessoa desde que usado sem fins comerciais. 0 trabalho é disponibilizado sob a licença Creative Commons CCBY-NC. 


\section{H. INTERACÃO EM 4. PSICOLOGIA}

Este artigo apresenta parte dos resultados de uma pesquisa de mestrado, em que se investigou a convivência na escola, analisando-se as interações entre os alunos, e os alunos e os professores, em três turmas de terceiro ano do Ensino Fundamental, de uma escola da rede municipal de uma cidade do interior de São Paulo. A investigação, realizada sob a forma de pesquisa-intervenção, nasce da demanda da escola e em específico das professoras, que alegavam já haver, no $3^{\circ}$ ano, manifestações de falta de interesse pelas atividades pedagógicas que resultavam no que se convencionou chamar de indisciplina. Segundo a gestão, a dinâmica resultante desta forma de relação estaria inviabilizando o ensino e a consequente aprendizagem dos alunos que, no penúltimo ano do primeiro ciclo do Ensino Fundamental, não dominavam habilidades de leitura e escrita esperadas para a idade/série. De modo a nos aproximarmos do contexto e estabelecer um vínculo mais próximo com os alunos e as turmas, propusemos desenvolver um projeto de intervenção em parceria com as professoras, utilizando histórias como mediação, por entender que este tipo de produção cultural mobiliza a imaginação, função psicológica prevalente na idade em que se encontravam os alunos.

Da perspectiva teórica que sustenta a pesquisa, compreende-se que, a um só tempo, social e sujeito se constituem nas interações. Para Vigotski (2005), é por meio do processo de internalização da cultura, mediado no e pelo social, que o sujeito se singulariza, ao mesmo tempo em que atua sobre o social, construindo-o, em um movimento dialético permanente. Por isso, evidencia-se o social, o meio, como fonte de desenvolvimento, fundamental aos processos constitutivos humanos.

Esse processo de humanização, compreendido aqui como as relações sociais que promovem a apropriação e domínio dos instrumentos produzidos pela cultura humana, não é dado a priori, o que significa dizer que, embora o homem nasça potencialmente humano, é por meio das interações concretas que estabelece as bases materiais de sua existência, ou seja, é no devir que radicam as possibilidades de seu desenvolvimento. Devir entendido como acesso à cultura. Vigotski (1997) utiliza o termo cultura em contraposição à natureza. Para o autor, o homem teria dois nascimentos um natural, do âmbito do biológico, em que apresenta as condições para se tornar humano; e um cultural, relativo às produções humanas, instrumentais ou simbólicas, que deverão ser apropriadas ao longo de seu desenvolvimento nas interações que empreenderá. Desta perspectiva, para o autor, a natureza do desenvolvimento psicológico é cultural. Em suas palavras: "O desenvolvimento cultural da criança [...] representa um nível de desenvolvimento completamente novo, o qual não só é insuficientemente estudado como geralmente não é distinguido na psicologia da criança" (1997, p. 97).
Se, por um lado, o social assume desta perspectiva um papel importante na constituição do sujeito, por outro, não se nega sua singularidade. Há algo no sujeito que lhe é particular, constituído a partir dos significados e sentidos que atribuiu às suas vivências e experiências. Justifica-se, assim, a afirmação de Vigotski (1997) de que a investigação da conduta e do pensamento humano implica a compreensão do afetivo-volitivo, que atua como força motriz de toda ação e pensamento. Parafraseando o autor (Vigtski, 2005, p. 130), para compreender o outro é preciso antes compreender os motivos que estão na base de suas ações e pensamentos.

Considerando que o meio social é fonte do desenvolvimento (Vigotski, 2010), pode-se presumir o lugar privilegiado que ocupa a escola como promotora deste desenvolvimento, sobretudo pela sua atribuição social de transmitir às novas gerações o legado da cultura humana, e, ainda, por poder possibilitar ao sujeito a apropriação de novas formas de estar, pensar e agir no mundo. 0 meio aqui aludido é mais que o espaço físico, refere-se também aos valores e crenças que guiam nossa sociedade. A ideia inovadora que o autor confere ao meio é toma-lo como situação social de desenvolvimento, o que supõe o modo como a criança o vivencia, entendendo que cada situação vivida impõe uma determinada emoção, uma dada percepção e compreensão que faz com que a criança se aproprie de significados e sentidos singulares. Esta acepção é cara à educação, pois implica refletir sobre as vivências que cada sujeito tem das situações que envolvem sua história, sua experiência e são, necessariamente, singulares.

Para que o desenvolvimento ocorra é imprescindível que a criança acesse a cultura, entendida por Vigotski (2010) como "forma ideal". Ideal no sentido de que consiste em um modelo daquilo que deve ser obtido ao final do desenvolvimento, e final no sentido de que representa as formas da cultura produzida pelo homem (Vigotski, 2010, p. 693). E, para explicar esse complexo processo de constituir-se por meio do acesso à cultura, o autor propõe o conceito de vivência, que seria uma unidade na qual se fundem o meio e a relação do sujeito com seus elementos, quais sejam, por um lado, aquilo que é externo à pessoa e, por outro, o que é vivido pelo sujeito. A vivência, então, representaria a união entre meio e sujeito, conceito que quebra a dicotomia atribuída à compreensão de Vigotski sobre o desenvolvimento, que oporia externo/interno, subjetivo/objetivo, intersubjetivo/intrasubjetivo (Gonzalez Rey, 2007).

Para os propósitos deste artigo, em que se busca analisar as interações na promoção do envolvimento de alunos com as atividades pedagógicas, optamos por utilizar o conceito de vivência entendida como experiência carregada de emoções, que possibilita a configuração de novos sentidos, de tomada 


\section{H NTERAC̄öEM ET PSICOLOGIA}

de consciência e de transformação de si e do outro (Souza \& Andrada, 2013; Petroni, 2012).

Essas explicações nos conduziram a eleger a convivência na escola como foco de nossa investigação por entendê-la como situação social de desenvolvimento que promove a vivência enquanto experiência significativa para as crianças.

\section{MÉTODO}

\section{CONSIDERAÇÕES SOBRE A ABORDAGEM QUALITATIVA EM PESQUISAS}

Consideramos esta pesquisa um estudo de abordagem qualitativa de tipo participativo, com características de pesquisa-intervenção. Tal delineamento está de acordo com o referencial materialista histórico e dialético da Psicologia Histórico-Cultural, no qual se ancora.

Afinados com o método do materialismo histórico-dialético, acreditamos na necessidade de um contato próximo e prolongado com os sujeitos e fenômenos investigados, considerando o contexto e cenário que os constituem.

Buscamos modos de pesquisar que desvelem o objeto de estudo. Em decorrência, nossa relação com o campo de pesquisa tem se dado dentro do paradigma participante ou participativo, em que propomos intervenções a fim de por em movimento o fenômeno investigado e, para tal, temos lançado mão de materialidades mediadoras ${ }^{1}$. No caso desta pesquisa, com alunos dos terceiros anos do Ensino Fundamental, optamos pelo uso da história, em suas diferentes modalidades e gêneros.

A proposta de contação e produção de histórias com os alunos têm como referencial os trabalhos de Montezi \& Souza (2013) e Barbosa (2012), que se utilizaram desta estratégia com adolescentes a fim de investigar o papel da imaginação e o sentido do respeito, respectivamente.

Para fundamentar o papel da história no desenvolvimento da imaginação, Barbosa (2012) assevera que:

[...] a arte de escrever e contar histórias existe desde os mais remotos tempos da humanidade. Na época das cavernas, o homem registrava suas experiências com a finalidade de comunicar-se com outros povos e gerações. Desde então, as histórias permitiram a transmissão de valores, crenças e conhecimentos, ligando o passado ao presente e guiando as ações e pensamentos da sociedade (p. 53).

Enquanto estratégia de intervenção do psicólogo na escola, a contação de história possibilita a criação de um contexto que produza o interesse das crianças e jovens, de modo que eles se envolvam com o enredo e se disponham a refletir so- bre as situações narradas. A relação entre a psicologia e as diferentes formas de literatura não é nova. As obras de Vigotski estão repletas de citações literárias que ele utiliza como recursos para explicar o psiquismo humano ${ }^{2}$. Portanto, nossa opção em utilizar a contação de histórias como uma estratégia de pesquisa-intervenção se sustenta no pressuposto teórico por nós assumido e nos trabalhos já realizados por membros do grupo de pesquisa a que se vincula.

\section{CARACTERIZAÇÃO DA INSTITUIÇÃO}

A instituição na qual se desenvolveu a pesquisa é uma escola municipal de Ensino Fundamental, localizada em um bairro periférico de Campinas, que atende à alunos de baixa renda. Foi fundada em 1980 e, desde 2007 tem parceria com o grupo de pesquisa a que se vincula este trabalho, que desenvolve intervenções com a gestão, professores e alguns grupos de adolescentes. Segundo os registros da escola, em 2012 havia 1011 alunos matriculados, 885 cursavam o Ensino Fundamental; e 126 a Educação para Jovens e Adultos (EJA). Contava com um diretor, dois vices diretores e dois orientadores pedagógicos, responsáveis pela gestão, 37 professores efetivos e 3 adjuntos, além funcionários de apoio na secretaria e limpeza.

\section{PARTICIPANTES}

Participaram desta pesquisa três turmas do $3^{\circ}$ ano do Ensino Fundamental, que se compunham de três professoras (uma de cada turma) e dos alunos, em média de 30 em cada turma, com idades entre 8 e 9 anos. As professoras tornaramse parceiras deste projeto, autorizando sua realização durante as aulas, ao longo do segundo semestre de 2012, e participando da elaboração do projeto e das intervenções com as crianças.

\section{DELINEAMENTOS DA PESQUUISA}

Primeiramente, realizamos uma reunião com os gestores da escola, em que apresentamos a intenção de realizar a pesquisa e solicitamos a indicação de professores para o estabelecimento de parcerias. Foi marcada uma reunião com as três docentes indicadas, momento em que a psicóloga-pesquisadora se apresentou, propôs a realização do projeto e a parceria com as docentes, acolheu as queixas das professoras, levantou informações sobre as turmas e, por fim, efetivou a participação destas professoras na pesquisa por meio da assinatura do Termo de Consentimento Livre e Esclarecido. Os horários foram combinados de modo a não atrapalhar a rotina das turmas.

No início do trabalho, a psicóloga-pesquisadora observou 


\section{INTERACÃO EM LF PSICOLOGIA}

as interações nas salas de aula uma vez por semana, durante uma hora em cada uma das três turmas. Neste momento, (primeira fase), explicou aos alunos que estaria frequentando a turma uma vez por semana, com o objetivo de observar de que modo eles se relacionavam com as atividades que desenvolviam. As observações ocorreram durante o mês de setembro. Inicialmente, a psicóloga-pesquisadora, durante o intervalo dos alunos, conversava com as docentes a fim de levantar as observações delas sobre as turmas. Posteriormente, as docentes passaram a utilizar estes momentos para conversar sobre os alunos que, segundo elas, requeriam um olhar mais atento, seja por comportamentos agressivos, dificuldades acadêmicas, dificuldade de relacionamento, etc. Os registros das observações foram utilizados na produção de diários de campo, elaborados logo após a saída da pesquisadora a cada encontro.

Ao constatar que a contação de histórias fazia parte da rotina de atividades das três turmas, optou-se por utilizar esse espaço para a atuação da psicóloga-pesquisadora, que conversou com as professoras a respeito e teve a proposta aprovada por todas. As docentes, nesta ocasião, deram várias sugestões e consentiram em ceder o momento de contação de histórias, uma vez por semana, para as atividades da pesquisadora. Também concordaram com a gravação em áudio desses encontros.

Produziu-se, então, um projeto que foi apresentado, discutido e reformulado juntamente com as professoras e instituída forma de acompanhamento semanal da atividade, quando as professoras sentavam com a pesquisadora para discutir e replanejar o projeto. A gestão também dispunha do projeto para acompanhar.

No mês de outubro teve início a segunda fase do projeto, com as atividades de contação. Convidamos os alunos a modificarem o espaço da sala de aula: juntos, afastávamos as carteiras, estendíamos faixas de TNT azul no chão e sentávamos em círculo. Na contação, utilizavam-se recursos de imagem para mostrar aos alunos e, ao seu final, a pesquisadora fazia perguntas para provocar uma conversa sobre a história. As professoras participavam do momento, chamando a atenção das crianças para o que estava sendo questionado. A princípio, os alunos não se envolveram muito e começamos a questionar o gênero que elegemos para contar.

0 vínculo com as docentes parecia consolidado; nas conversas com a psicóloga-pesquisadora elas apresentavam uma crescente narrativa de aspectos cotidianos da sala de aula e de suas atividades na docência. Para preservar suas identidades optou-se por nomeá-las com nomes fictícios de personagens de Mauricio de Souza. As chamaremos de Professora Monica, Professora Magali e Professora Rosinha.

Dadas as observações e conversas com as docentes foi se reconstruindo a seleção de histórias, mas ainda os alunos não se mostravam muito motivados e começaram a pedir histórias de terror. No final de outubro, 3 meses após meu ingresso com as professoras, todas fomos surpreendidas com a troca de docentes. As professoras que ali estavam desde o início do ano letivo eram adjuntas ${ }^{3}$ e as concursadas, portanto, efetivas haviam sido convocadas a assumirem as salas, o que ocorreu imediatamente, sem tempo, inclusive, para uma transferência de vínculo com os alunos.

Chamei de $3^{a}$ fase da pesquisa, que se caracterizou por um novo começo, novo gênero literário - o terror; e novas professoras, a quem chamamos de Professora Minnie, Professora Margarida e Professora Clarabela. Foi realizada uma apresentação da proposta e das atividades que vinham sendo desenvolvidas, as quais as professoras concordaram em dar continuidade, sendo mantida a dinâmica dos encontros, entretanto com uma participação menos ativa das docentes.

Observou-se, no entanto, mesmo introduzindo o gênero terror, menos envolvimento dos alunos, que pediram outras histórias de terror. E assim, outras 3 histórias foram levadas, mas o que os alunos queriam mesmo era contar suas histórias, em geral baseadas em lendas urbanas, envolvendo fantasmas, cemitérios, "loira do banheiro", dentre outras. Abriu-se espaço, então, para que eles contassem as histórias que gostavam.

Nas duas semanas seguintes, ainda buscando envolve-los com a apreciação de histórias, a psicóloga-pesquisadora levou o livreto "Histórias de Adolescentes, Histórias para Adolescentes" (2012). Este material é fruto da pesquisa de Mestrado de Barbosa (2012), e apresenta histórias produzidas durante o ano letivo de 2011, por alunos do sexto ano do Ensino Fundamental, de uma escola estadual do interior do estado de São Paulo. Tratam-se de histórias simples, curtas, com enredo envolvendo poucos personagens e temas do universo dos jovens.

As histórias agradaram muito os alunos, que pediam mais e mais, o que resultou na leitura de quase todas as histórias do livro. Também foi contada aos alunos a origem do livreto, o que thes causou grande surpresa. Nas turmas das professoras Minnie e Margarida os alunos pediram para criar suas próprias histórias para elaboração de um livro semelhante, atividade esta que já havia sido planejada, constituindo-se como um de nossos objetivos no desenvolvimento dos encontros.

A $4^{\mathrm{a}}$ fase do projeto, dedicada à produção de histórias pelos alunos, constitui-se como rico momento de envolvimento de todos. A psicóloga-pesquisadora ofereceu diferentes tipos de papeis e riscadores, além de tesoura e cola e disponibilizou todas as histórias já contadas de modo que pudessem consultá-las. A pedido dos alunos, construíram as histórias 


\section{W INERACÄOEM ET PSICOLOGIA}

em grupo, segundo suas escolhas e organização.

Quando os alunos finalizaram suas histórias, a psicólogapesquisadora conversou sobre o desenvolvimento do grupo e seu encerramento. Expôs as histórias que foram contadas e convidou os alunos a produzirem um cartaz sobre os encontros.

As histórias produzidas pelos alunos foram digitadas buscando-se manter a grafia e organização do texto como redigido por eles. Totalizaram 77 produções, 21 da turma A, 34 da turma B e 22 da turma C. Deste total, 42 histórias, 54\% tinham começo, meio e fim. 17,22\%, não tinham fim, e 22 histórias, representando $28 \%$, não puderam ser digitadas por não ser possível decifrar a escrita.

Essas informações nos colocaram frente a um dilema: a pesquisa, que tinha como objetivo analisar a convivência entre professores e alunos e alunos e alunos, acaba por desvelar aspectos relativos à aprendizagem, à apropriação de conhecimento fundamental ao desenvolvimento de crianças entre 8 e 9 anos de idade: o domínio da leitura e da escrita. Põe em evidência, também, a convivência entre as docentes e a gestão, a gestão e os alunos, a gestão e o sistema de ensino. Este fato nos conduziu a fazer recortes e organizar a análise com foco nas interações, buscando oferecer explicações para o modo como os alunos se relacionavam com as atividades, o que poderia iluminar uma melhor compreensão sobre o desempenho dos alunos na escrita. Entretanto, acendeu um alerta sobre outras pesquisas e intervenções que necessitam se inserir na escola.

\section{RESULTADOS E DISCUSSÃO}

\section{COMO EM UM ESPELHO: ASSIM REFLETIRAM AS INTERAÇÕES NAESCOLA}

A opção por realizar uma pesquisa, em que se objetiva analisar as interações escolares com vistas a identificar práticas que favoreçam a convivência como promotora do desenvolvimento e da aprendizagem dos alunos, está fundamentada na compreensão de que as relações sociais, mediadas sobretudo pela palavra, são a principal fonte do desenvolvimento psicológico, que resulta em novas formas de ser, estar, pensar e agir no mundo (Vigotski, 2010).

Compreende-se, portanto, que a aproximação e apropriação pelos sujeitos do conhecimento científico, é favorecida pela escola, espaço privilegiado de circulação do conhecimento formal. Vejamos, da perspectiva de uma criança, aluna de uma das turmas pesquisadas, a representação desta interação:

\section{Vera Lucia Trevisan de Souza e Ana Flávia Silva Luz}

Eu a cordei com priquisa minha mãe saio ela disse:

Faz todo deve de casa.

Eu esquesi de faze pare seu um homem eu cai ele melevou para cama minha mãe chegol minha mãe ele de saparecel era todo um pesadelo eu fis todo o deve de casa mesmo assim cendo um pesadelo.

A história acima é produção de uma das alunas da turma A, a partir da proposta de escrita de histórias, conforme explicitado nas páginas precedentes. A densidade e profundidade do conteúdo nela expressas revelam o conflito vivido pela criança envolvendo a autoridade da mãe, a demanda da escola, seu desejo de permanecer dormindo e o medo de não atender a determinação da mãe, representado pelo pesadelo: um homem estranho que a faz cair da cama, mas a leva de volta, porque ela faz o dever de casa.

Dever que é um pesadelo, que se esquecido coloca a criança a mercê de um homem, um desconhecido que ao mesmo tempo ameaça e a leva para a mãe, que concomitantemente a socorre e a pune, por não ter feito o dever. E o pesadelo revela um paradoxo: o dever de casa é o próprio pesadelo e a um só tempo, não o fazê-lo gera o pesadelo, o medo.

Esse modo com que a criança interage com a escola, com os deveres, com a mãe, expresso tão espontaneamente em uma história em que a aluna faz uso da imaginação, precisa ser considerado como uma experiência significativa, que vai sim influenciar a aprendizagem dessa criança. E evidencia claramente que as mediações que concorrem nas interações em sala de aula têm elementos que ultrapassam a situação vivida na escola, o que já insere um caráter complexo que precisa ser considerado ao abordar as interações em sala de aula. É sobre esse aspecto que vamos discutir mais adiante.

Os dados analisados advêm dos diários de campo e das histórias produzidas pelos alunos das três turmas. É preciso destacar que a produção escrita dos alunos não se configurava, originalmente, como objeto de análise deste estudo, entretanto, o acesso às histórias produzidas pelas crianças, nos encontros de intervenção nos provocou grande inquietação em relação às possibilidades de apropriação e produção escrita das crianças, em fase propícia a esse desenvolvimento. Acreditamos que não podemos deixar de considerar esse aspecto, o que implica o posicionamento crítico do pesquisador, tal como pressupõe o aporte teórico-metodológico que adotamos neste estudo.

Dando continuidade à análise proposta, importa considerar o modo como as docentes concebem as interações. 0 ex- 


\section{-4: INTERACÃO EM LF PSICOLOGIA}

certo a seguir expressa essa compreensão:

[Profa. Magali, sobre a proposta de pesquisa-intervenção] disse ser interessante observar as três salas dos terceiros anos, pois assim teria uma visão maior das possibilidades de relações. Observou que as turmas têm suas semelhanças, mas também suas singularidades. Afirmou que os alunos de sua turma e da professora Mônica são agitados, e atribuiu a isso o modo com que elas trabalham, disse que ela é uma pessoa muito agitada e que acabava passando isso para os alunos, em contrapartida a turma do $3^{\circ}$ ano $\mathrm{C}$, sala da professora Rosinha, é mais quieta, pois a profa. é calma e tranquila. (Trecho do DC 3).

Parece que, para essa docente, a influência que as professoras exercem sobre os alunos se dá por vias diretas e imediatas, ou seja, o modo de funcionamento do coletivo da sala de aula reflete os modos de ser singulares de cada docente. Logo, parece-nos que os alunos servem, para as docentes, como espelhos de seu próprio modo de funcionar, e que a imitação dessas formas de agir pode ser compreendida como influência positiva para o aluno.

Há muito orgulho na fala da professora quando ressalta a forma como os alunos imitam os seus modos de ser. A imitação é considerada por Vigotski (2010) como um processo dinâmico que favorece e possibilita a aprendizagem, visto que é por meio dela que os alunos aprenderão, internalizando o conhecimento a partir de seu próprio nível de desenvolvimento. Porém, destaca o autor que o aluno não imita tudo e qualquer coisa, mas somente aquilo que está dentro de suas possibilidades e que pode futuramente utilizar para resolver problemas ou chegar a determinados resultados.

Contudo, a fala da professora não remete à imitação das formas de apreender os conteúdos escolares, mas a imitação das formas de agir nos espaços de salas de aula. Tal modo de conceber as interações, como espelhos que refletem a si mesmos, pode se configurar como um fator impeditivo da problematização, pela docente, de suas práticas pedagógicas e dos seus próprios modos de agir em sala de aula, movimento que permitiria romper com a naturalização da seguinte compreensão: "os alunos são assim, porque eu sou assim, e não há o que fazer a respeito".

Outro fator que nos chama a atenção é relativo ao que a professora chama de agitação, o que pode ser significado como desorganização. Os excertos abaixo nos aproximam desse olhar:

[...] Nas aulas da professora Monica, observei que a maior parte do tempo ela fala muito e alto, conforme o volume de conversa dos alunos aumenta, ela aumenta seu tom de voz e por vezes chega a falar gritando, anda por toda a sala o tempo todo. A sala fica ao lado de árvores e nesta época do ano há grande concentração de cigarras, o can- to delas é frequente e muito alto, o que aumenta o baruIho, gerando grande incomodo, também para os alunos que reclamam várias vezes. Essa turma parece ser a mais agitada, falam muito, ficam em pé ao lado das carteiras, circulam pela sala, apontam o lápis, vão pegar a borracha emprestada com o colega. O barulho constante, de carteiras, cigarras, vozes, papéis, lápis faz com que seja exaustivo permanecer na sala. (Trecho do DC 10)

[...] A Profa. Monica propõe muitas atividades diferentes, diz que seus alunos são agitados e precisa mantê-los ocupados. Trabalha com recortes, construção de murais, passeios, kit multimídia, vídeos. As atividades eram muito interessantes, envolviam os alunos, mostrava a atenção e dedicação da docente, mas pareciam ser muito complexas para os alunos, de difícil realização. A professora Monica, sem dúvida é uma docente dedicada, se entrega à turma, planeja muitas atividades, mas estas parecem pouco organizadas. (Trecho de DC 9).

[...] O armário da docente [Monica] transborda material, muitas folhas, livros, recortes, revistas, desorganizados, amassados, empilhados, despencando. Em alguns momentos ela não encontra o que precisa, como, por exemplo, tesoura, cola, matriz de atividade, livro didático em quantidade suficiente para toda turma, não sabe se alguém não devolveu, ou se está em outro lugar. (Trecho do DC 11).

Os relatos apresentados nos colocam frente ao modo como a professora se organizava para cumprir suas atividades; ao mesmo tempo em que buscava apresentar aos alunos diferentes formas de aprender o conteúdo, lançando mão de diversas ferramentas, mostrava sua desorganização com o material. Esse era o cenário que constituía aquela sala, em específico, como um dos meios em que alunos e professora se inseriam.

Esses são aspectos que nos levam a questionar: quais seriam as influências exercidas por esse meio no desenvolvimento desses sujeitos? De que maneira contribuíam para a compreensão da professora de que os alunos se regulavam para atender àquela dinâmica?

Podemos tentar compreender essas influencias a partir do conceito de situação social de desenvolvimento, entendida, a partir da conceituação de Bozhovich (1965), como a combinação especial da relação do desenvolvimento psicológico interno e das condições externas, que resultarão em novas formas psicológicas qualitativamente distintas. Entendemos que as situações sociais de desenvolvimento promovidas pelos atores escolares, sobretudo pelos professores, são fundamentais na constituição das atitudes dos alunos frente à necessidade de apropriação dos conhecimentos que devem ser transmitidos pela escola. E, dialeticamen- 


\section{W'INTERACCÃO EM ET PSICOLOGIA}

te, as atitudes dos alunos nesse processo devem servir de diretrizes para o planejamento das ações pedagógicas com vistas a atingir os objetivos de ensino. As práticas pedagógicas, então, assumiriam uma dupla função: promover o ensino dos conteúdos escolares e desenvolver a curiosidade, o apreço e a perseverança das crianças em relação ao aprendizado, em outras palavras, de constituí-las como alunos (Bozhovich, 1965).

Para que o processo de ensino-aprendizagem se constitua com base nessas diretrizes é importante que as funções psicológicas envolvidas na aprendizagem sejam compreendidas, pelos atores escolares, como processo em construção, assim como o próprio conhecimento. E para tal é importante que as professoras assumam uma constante postura crítica em relação ao trabalho que desenvolvem.

Isso nos leva a considerar que muitas situações presentes na escola estão naturalizadas. Mas o que se está sendo naturalizando? E como esta naturalização é revelada nas interações da escola? É com vistas a elucidar essas questões que se discorre no próximo tópico.

A busca pelo controle do comportamento como característica da interação: empecilhos para o desenvolvimento da autonomia dos alunos e professores.

Temos visto, com o acesso aos mais diversos estudos existentes na área da Psicologia Escolar, a frequência com que algumas condutas e concepções têm sido naturalizadas e reproduzidas, haja vista as recentes discussões sobre a medicalização promovidas pelos Conselhos de Psicologia ou os trabalhos que versam sobre o fracasso escolar, assim como sobre a indisciplina nas escolas.

E, ao adentrarmos nas turmas, pudemos observar que algumas dessas naturalizações permeavam as interações estabelecidas entre professoras e alunos:

[Professora Mônica falando do comportamento dos alunos enquanto a ajudava a organizar as carteiras no final da aula] disse que levou um semestre para fazer com que ficassem daquela forma, que se sentassem nas carteiras, pois são extremamente agitados. (Trecho do DC 8).

[Professora Rosinha falando sobre os alunos e a rotina dentro e fora da sala de aula] a docente disse que precisava ficar com a turma durante o recreio, não podia deixar de vigiá-los porque eles aprontam todas, brigam e jogam comida uns nos outros. (Trecho do DC 4).

[...] Rosinha me pediu para observar com atenção um aluno, dando a entender que ele seria o causador de conflitos. (Trecho do DC 4).

[...] são determinados alunos que dão trabalho, nós já sa- bemos quem são, então redobramos a atenção. (Professora Magali, trecho do DC 3).

Destacamos alguns trechos nas falas por entender que têm algo em comum, que se manifesta como uma crença que permeia a escola: a vigilância e o controle, por si só, resolvem os conflitos e criam as condições para o desenvolvimento das crianças.

Desta perspectiva, nos questionamos em que medida o fato de as docentes expressarem uma concepção naturalizada de desenvolvimento, visto que bastaria controlar as crianças para resolver os problemas, interfere no processo de constituição das crianças e na própria interação. E mais, o que mobiliza as ações de controlar os alunos?

Um dos principais movimentos da naturalização é a centralização do potencial no outro e, consequentemente, a responsabilidade e culpa individualizada. Como sendo algo natural, próprio do sujeito, o outro da relação se exime da participação, da realidade. Pois bem, o questionamento central que nos colocamos é: que influências esse tipo de mediação tem nas atividades dos professores? Ou seja, o fato de entender que será preciso controlar o comportamento dos alunos o tempo todo, cerceia o planejamento de atividades mais dinâmicas e criativas a serem desenvolvidas com os alunos? É possível dizer que uma prática desenvolvida com esta preocupação restringe as possibilidades de ensino e aprendizagem?

Seria possível pensar a partir das falas acima que as próprias professoras produzem o modo de se relacionar com as crianças, pois ao concebê-las como naturalmente disciplinadas ou não, acabam por agir em relação a elas com essa expectativa, não observando as diferenças e possíveis mudanças. Entretanto, também é necessário considerar que as crianças, com seus modos de agir e pensar, atuam na produção das interações com a professora e entre si, fazendo com que as professoras desenvolvam atitudes e ações em relação aos alunos ou às práticas que desenvolve. Ou seja, as interações são produzidas em um complexo processo dinâmico e permanente, em que concorrem as concepções, os valores, os pensamentos e ações de todos os sujeitos, envolvidos direta ou indiretamente na situação, como é o caso, por exemplo, do currículo, da formação de professores, da organização da escola ou do sistema de ensino. Logo, não se trata de atribuir a responsabilidade da qualificação das interações como favorecedoras da aprendizagem e desenvolvimento das crianças apenas ao professor, mas, ao contrário, destacar as condições materiais em que se desenvolvem as práticas escolarizadas como condicionantes deste processo.

Como já pontuamos, a mediação é fundamental para que o desenvolvimento se efetive, sendo a escola espaço privilegiado para a construção e apropriação de normas de convi- 


\section{- H. INTERACÃO EM LF PSICOLOGIA}

vência, na medida em que se constitui como meio que oferece condições para que esse processo aconteça, ao oferecer a possibilidade de os sujeitos conviverem com o igual - crianças da mesma idade -, e o diferente - pessoas com diferentes crenças, valores, conhecimentos, costumes, - em um espaço comum, mediado por especialistas que tem a responsabilidade de educá-los. Logo, trata-se da possibilidade de diferenciar-se, percebendo-se, a um só tempo, como iguale diferente, e as suas interações são essenciais neste processo. No entanto, cabe destacar que para exercer seu papel os profissionais necessitam de muitas condições que precisam ser oferecidas, dentre as quais um espaço permanente de reflexão, de abertura às dúvidas e de nutrição de ações e práticas criativas.

Para Vigotski (2005), seria na interação, a partir do que vive com os outros, que o sujeito se torna capaz de ir se apropriando de modos de funcionar cada vez mais elaborados, rumo ao desenvolvimento qualitativo do sistema psicológico, em que as conexões entre as funções psicológicas assumem possibilidades quase infinitas.

A fala da professora Rosinha é um exemplo de mediação desta natureza e nos faz pensar que sua implicação com os alunos, mesmo no horário do intervalo, circula nas interações e é apropriada por eles. Por várias vezes observamos que os docentes, durante o intervalo, fecham-se na sala de professores e não se envolvem com os alunos. Entretanto, a ideia de acompanhar, observar os alunos fora da sala de aula, em outras atividades, deveria servir ao replanejamento das aulas a partir de um melhor conhecimento dos alunos, da identificação de potencialidades de alguns alunos que, por alguma razão, não se envolvem com as atividades em sala de aula. De outro lado, também observamos que as relações em sala de aula, muitas vezes, são desgastantes para a professora, que se esforça, a sua maneira, com suas ferramentas, para envolver e ensinar os alunos. Alguns alunos têm atitudes desrespeitosas no que concerne ao espaço de convivência e, à autoridade da professora, contribuindo para criar um clima de animosidade que afeta a professora, levando-a a se perder na condução da sala. Então a parada no intervalo é saudável, é tempo de pausa, de "respiro". Essas observações revelam a complexidade que caracteriza as relações de ensino e aprendizagem quando se considera o papel formador de valores da escola.

Nossa defesa é do diálogo e pelo diálogo - em todas as instâncias, dentro e fora da escola. Esta estratégia é que favorece a autorregulação, visto que é pela compreensão dos significados e atribuição de sentidos ao que a regra de funcionamento coletivo estabelece que o aluno se apropriará dela e conseguirá respeitá-la independentemente de regulação externa. Ao contrário do que se almeja, as interações mediadas por excessiva regulação externa favorece a heteronomia do sujeito, visto que este não compreende o quê e o porquê de não poder fazer algo, entende apenas que quando a professora estiver olhando não dá para ter esta ou aquela atitude (Souza, 2004).

Um exemplo do uso da regulação externa, no caso de caráter ameaçador, pode ser observado nos excertos abaixo:

[...] quando a docente se ausentou da sala, imediatamente um aluno se levantou e ficou ao lado da lousa anotando os nomes dos colegas que estavam em pé. (Turma da professora Monica, trecho do DC 13)

[...] os alunos queriam falar, todos ao mesmo tempo, e alguns chamavam a atenção dos outros utilizando a mesma forma da professora, gritavam "olha a regra número 3", "não pode falar todo mundo junto". (Turma da professora Monica, trecho do DC 12).

Interessante observar nos trechos acima dois exemplos de conteúdo de interação: um que reproduz práticas de controle e de delação, que em nada contribuem para o desenvolvimento dos alunos, e outra com grande potencial para transformação das relações e promoção do desenvolvimento, visto indicar que os próprios alunos estão se autorregulando a partir do diálogo com as regras de convivência, que eles próprios ajudaram a construir.

Tardif (2002) afirma que são as interações humanas que se configuram como o núcleo da docência, na medida em que são elas que determinam a natureza das práticas pedagógicas. Segundo o autor:

[...] se o ensino é mesmo uma atividade instrumental, trata-se de uma atividade que se manifesta concretamente no âmbito das interações humanas e traz consigo, inevitavelmente, a marca das relações humanas que a constituem. Nesse caso pode-se dizer que o professor é um "trabalhador interativo" (2002, p. 118).

Partindo deste pressuposto, as interações em sala de aula devem servir de material para que o professor planeje as suas atividades de modo a favorecer e viabilizar a apropriação dos conteúdos escolares pelos alunos, além de modos de ser e estar no coletivo. Diante do exposto, não podemos deixar de nos perguntar se as professoras percebem as interações estabelecidas em sala de aula como estratégias de trabalho, e os trechos de fala abaixo nos ajudam nessa compreensão:

[...] a gente é assim, uma mais agitada, outra mais calma, é como somos, e as aulas, as turmas têm a nossa cara. (Profa. Mônica, trecho do DC 9).

[...] você vai ver muita diferença entre as turmas, mas 


\section{H*' INTERACÃO EM LF PSICOLOGIA}

também entre as professoras, cada uma tem uma forma de condução mesmo que os conteúdos e as atividades sejam as mesmas. (Profa. Rosinha, DC 4).

[...] a turma segue minha forma de trabalho. Eles são falantes e agitados como eu, tem um pouco do meu jeito. (Profa. Magali, trecho do DC 6).

Parece que o que emerge destas expressões é uma compreensão unilateral e simplista de um fenômeno muito complexo, que deveria ser compreendido como construído social e coletivamente. 0 "jeito" do professor assume prevalência na construção das práticas pedagógicas. Não se quer, com esta afirmação, negar que as singularidades do professor interfiram nas formas de condução das aulas, o que para nós é um fato. Contudo, o que nos chama a atenção é que, ao que nos parece, nestas práticas a referência é a professora, e não a interação que se retroalimenta permanentemente, a partir das relações entre as docentes e os alunos, que seriam a um só tempo, autores e atores dos processos de ensino-aprendizado dentro das salas de aula.

Estes modos de se relacionar e que parecem estar na base da constituição das práticas pedagógicas dos docentes, não são favorecedores do desenvolvimento de uma consciência crítica sobre sua própria atuação, visto que, para que a mesma se desenvolva, como afirma Freire (2008), é preciso encarar a realidade como mutável. Concepção esta não compartilhada pelas professoras, já que entendem o modo de se comportar dos alunos em sala como diretamente ligado ao seu modo de ser, ou seja, é assim mesmo e não há o que fazer a respeito, a não ser criar formas de regular seu comportamento. Por outro lado, alija os alunos da possibilidade de apropriação dos conteúdos escolares, sobretudo pelo não compartilhamento de significados e sentidos do que é tratado em sala de aula, a começar pelas regras e normas sociais.

\section{CONCLUSÃO}

No momento em que tecemos as considerações finais deste estudo, cabe retomar seu objetivo: analisar as interações na escola, notadamente entre alunos e professores dos terceiros anos do Ensino Fundamental, visando identificar práticas que favoreçam a convivência como promotora do desenvolvimento e aprendizagem dos alunos.

Já em nossas primeiras inserções, por meio do projeto de contação de histórias, pudemos observar que cada uma das três turmas apresentava singularidades concernentes ao domínio da leitura e da escrita e no modo como as relações eram estabelecidas entre os alunos, e entre estes e o professor.

A produção textual dos alunos nos inquietou ainda mais, sobretudo pela dificuldade observada na maioria dos alunos no momento de escrever e no resultado da produção. Esse fato nos remeteu às disposições gerais da Educação Básica e nos perguntamos em que medida os objetivos da educação estariam sendo alcançados.

Ao focalizarmos as interações visando compreender como têm se configurado as relações que se estabelecem na escola e em que medida são favorecedoras de convivência promotora de desenvolvimento, vimos que a tentativa de controlar o comportamento das crianças parece assumir primazia nas práticas das docentes e da escola. Práticas estas reproduzidas pelos alunos, revelando que se apropriam dos conteúdos que permeiam as interações. A questão que permanece é relativa à percepção ou não dos professores sobre esse processo: os alunos se apropriam também de conteúdos que não ensinam, mas circulam nas interações e são significados por eles, que atribuem sentidos singulares ao que vivenciam. Acessar esses significados seria uma forma de conhecer os valores, as crenças, o pensamento das crianças sobre o mundo e sobre si próprio no mundo. Uma prática promotora de desenvolvimento, sem dúvida. Mas os professores precisam de condições materiais de trabalho que viabilizem esta reflexão e essas ações, o que remete diretamente a políticas educativas, às ações do sistema de ensino, à organização da unidade escolar, questões que permanecem como temas de outras pesquisas que busquem compreender como a atuação dessas diversas instâncias aportam na escola e interferem nos resultados por ela produzidos no que concerne ao desenvolvimento de uma educação de qualidade.

\section{CONTRIBUIÇÃO DE CADA AUTOR}

V.L.T.S realizou a supervisão da pesquisa; contribuiu na redação - revisão e edição. A.F.S.L. conduziu a investigação; realizou a redação - preparação do rascunho original

\section{DECLARAÇÃO DE CONFLITOS DE INTERESSES}

Os autores declaram que não há conflitos de interesses no presente artigo.

\section{DECLARAÇÃO DE FINANCIAMENTO}

O artigo provém da dissertação de mestrado de A.F.S.L., sendo esta financiada pelo CNPq.

\section{REFERÊNCIAS}

Barbosa, Eveline T. (2012) Os sentidos do respeito na escola: Uma análise da perspectiva da psicologia histórico-cultu- 


\section{U NTERAC̄öEM ET PSICOLOGIA}

ral. Dissertação de mestrado, Pontifícia Universidade Católica de Campinas, Campinas, SP.

Bozhovich, L.I. \& Blagonadiezhina, L.V. (1965) Psicologia de la personalidad del niño escolar. Editora del Consejo Nacional de Universidades. La habana.

Freire, P. (2008). Educação e mudança (31ª ed). São Paulo: Paz e Terra. (Trabalho original publicado em 1979)

González Rey, Fernando. (2007). As categorias de sentido, sentido pessoal e sentido subjetivo: Sua evolução e diferenciação na teoria histórico-cultural. Psicologia da Educação, 24, pp.155-179.

Montezi, A. V. \& Souza, V. L. T. (2013). Era uma vez um sexto ano: Estudando imaginação adolescente no contexto escolar. Psicol. Esc. Educ., 17(1), p.77-85.

Petroni, Ana Paula. (2012). Psicologia escolar e arte: Possibilidades e limites da atuação do psicólogo na promoção da ampliação da consciência de gestores. Tese de Doutorado - Programa de Pós Graduação em Psicologia, Pontifícia Universidade Católica de Campinas - Campinas, SP.

Souza, Vera Lucia Trevisan (2004). A interação na escola e seus significados e sentidos na formação de valores: Um estudo sobre o cotidiano escolar (Tese de doutorado). Pontifícia Universidade Católica de São Paulo, São Paulo, SP.

Souza, V.L.T., Petroni, A.P. \& Dugnani, L.A.C. (2011). A arte como mediação nas pesquisas e intervenção em Psicologia Escolar. Em R. S. L. Guzzo \& C. M. Marinho-Araujo. Psicologia escolar: Identificando e superando barreiras (pp. 261285). Campinas, SP: Editora Alínea.
Souza, V.L.T. \& Andrada, P.C. (2013). Contribuições de Vigotski para a compreensão do psiquismo. Estudos de Psicologia(Campinas), 30(3), pp. 355-366. http://dx.doi.org/10.1590/S0103-166X2013000300005

Tardif, M. (2002). Saberes docentes e formação profissional. Rio de Janeiro: Vozes.

Vigotski, L.S. (1997). Fundamentos da Defctologia. Obras Escolhidas. Tomo V. Madrid: Visor

Vigotski, L. S. (1999). The collected works of L. S. Vygotsky, Tomo VI. (M. J. Hall, Trad.) Nova Iorque: Kluwer Academic/Plenum Publishers.

Vigotski, L. S. (2005). Pensamento e linguagem (3a. ed.). (J. L. Camargo, Trad., J. Cipolla Neto, Rev. Tec.). São Paulo: Martins Fontes. (Trabalho original publicado em 1934).

Vigotski, L. S. (2010). Quarta aula: A questão do meio na pedologia, Lev Semionovich Vigotski. (M.P. Vinha \& M. Welcman, Trad). Psicologia USP, 21(4), pp. 681-701. http://dx.doi.org/10.1590/S0103-65642010000400003 (Obra original publicada em 1935.)

Recebido em: 20/03/2014 Primeira decisão editorial em: 18/01/2017 Aceito em: 28/04/2017

\footnotetext{
1 "Materialidades porque se trata de símbolos da cultura, mais precisamente a arte, e mediadoras porque acreditamos que seu uso pode acessar a subjetividade dos sujeitos, favorecendo sua expressão e promovendo o desenvolvimento da consciência de si e do outro" (Souza, Petroni \& Dugnani, 2011, p. 265)

2 Um exemplo de grande destaque é seu estudo sobre "A tragédia de Hamlet, príncipe da Dinamarca" (Vigotski, 1999), onde o autor parte da produção literária de Shakespeare para desenvolver um de seus primeiros estudos sobre o desenvolvimento humano.

${ }^{3}$ Segundo a Resolução SME 05/2009, que regulamenta o trabalho do Professor Adjunto em Campinas, o artigo $1^{\circ}$ declara que "o cargo de Professor Adjunto destina-se, prioritariamente, à substituição para o exercício das funções de docência sempre que se configurar ausência, a qualquer título, dos titulares de cargo do grupo de professores". Disponível em http://www.campinas.sp.gov.br/bibjuri/r05-14052009.htm

4 Texto digitado conforme a redação da aluna.
} 